MSC 60H30

DOI: $10.14529 / \mathrm{mmp} 170401$

\title{
SOME MATHEMATICAL MODELS WITH A RELATIVELY BOUNDED OPERATOR AND ADDITIVE "WHITE NOISE" IN SPACES OF SEQUENCES
}

\author{
K.V. Vasyuchkova, N.A. Manakova, G.A. Sviridyuk \\ South Ural State University, Chelyabinsk, Russian Federation \\ E-mail: vasiuchkovakv@susu.ru,manakovana@susu.ru, sviridyuk@susu.ru
}

\begin{abstract}
The article is devoted to the research of the class of stochastic models in mathematical physics on the basis of an abstract Sobolev type equation in Banach spaces of sequences, which are the analogues of Sobolev spaces. As operators we take polynomials with real coefficients from the analogue of the Laplace operator, and carry over the theory of linear stochastic equations of Sobolev type on the Banach spaces of sequences. The spaces of sequences of differentiable "noises" are denoted, and the existence and the uniqueness of the classical solution of Showalter - Sidorov problem for the stochastic equation of Sobolev type with a relatively bounded operator are proved. The constructed abstract scheme can be applied to the study of a wide class of stochastic models in mathematical physics, such as, for example, the Barenblatt - Zheltov - Kochina model and the Hoff model.
\end{abstract}

Keywords: Sobolev type equations; Banach spaces of sequences; the Nelson - Gliklikh derivative; "white noise".

\section{Introduction}

Let us consider an abstract mathematical model of the form

$$
L \dot{u}=M u+f,
$$

which is the prototype of the Barenblatt - Zheltov - Kochina model [1] and Hoff model [2]. Operators $L=L(\Lambda)$ and $M=M(\Lambda)$ are the polynomials with real coefficients; the operator $\Lambda u=\left(\lambda_{1} u_{1}, \lambda_{2} u_{2}, \ldots\right)$ acts in the spaces of sequences $[3,4]$

$$
l_{q}^{m}=\left\{u=\left\{u_{k}\right\}: \sum_{k=1}^{\infty} \lambda_{k}^{\frac{m q}{2}}\left|u_{k}\right|<\infty\right\}, m \in \mathbb{R}, q \in[1,+\infty),
$$

which are the analogues of Sobolev spaces $W_{q}^{m}$; the sequence $\left\{\lambda_{k}\right\} \subset \mathbb{R}_{+}$is a monotonically increasing sequence, such that $\lim _{k \rightarrow \infty} \lambda_{k}=+\infty$. For the equation (1) we will consider the Showalter - Sidorov condition

$$
P\left(u(0)-u_{0}\right)=0,
$$

where $P$ is a relatively spectral projector. A study of positive solutions is started in [5], where the sufficient conditions for the existence of a single positive solution of the Showalter - Sidorov problem (1), (2) in Sobolev spaces of sequences that can be interpreted as the space of Fourier coefficients of solutions initial-boundary value problems are given [6]. 
This article (as, indeed, [5]) is inspired by the fundamental work [7], where it is suggested to use degenerate holomorphic resolving groups of operators whose construction is based on the theory of degenerate groups of operators to find solutions to the problem (1), (2). We apply developed in [5] methods to the search of the stochastic solutions of the equation

$$
L \stackrel{o}{\eta}=M \eta+N \Theta
$$

equipped with a weak (in the sense of S.G. Kreign) condition of Showalter - Sidorov

$$
\lim _{t \rightarrow 0+} P\left(\eta(t)-\eta_{0}\right)=0 .
$$

Here, operators $L, M$ and $P$ are the same as above, the operator $N$ will be defined later, $\eta=\eta(t)$ is a stochastic process we are looking for, and $\Theta$ are the given stochastic process; by the symbol $\stackrel{o}{\eta}$ the Nelson - Gliklikh derivative of the stochastic process $\eta=\eta(t)$ is denoted.

The paper is organized as follows. The first part is preliminary nature. It presents our approach to studying stochastic $K$-processes. The foundations of this approach are laid in [8], then developed in [9-11]. Here also by analogy with [12] the spaces of sequences of differentiable "noises" are introduced into consideration. In the second section the abstract problem (3), (4), where the operator $M$ is $(L, p)$-bounded, $p \in\{0\} \cup \mathbb{N}$, is considered. We notice that our approach is based on the Nelson - Gliklikh derivative [13], the theory of (semi)groups of operators [7], which distinguishes it from the classical Ito - Stratonovich Skorokhod approach (see, for example, [15]) and recently the emerged Melnikova - Filinkov approach [16].

\section{Stochastic $K$-Processes}

Let us consider the complete probability space $\Omega \equiv(\Omega, \mathcal{A}, \mathbf{P})$ and the set of real numbers $\mathbb{R}$, endowed with a Borel $\sigma$-algebra. Following [8], we call a measurable mapping $\xi: \Omega \rightarrow \mathbb{R}$ a random variable. A set of random variables, which mathematical expectations are equal to zero, forms a Hilbert space $\mathbf{L}_{\mathbf{2}}$ with scalar product $\left(\xi_{1}, \xi_{2}\right)=\mathbf{E} \xi_{1} \xi_{2}$, where $\mathbf{E}$ is the mathematical expectation of a random variable. We denote by $\mathcal{A}_{0}-\sigma$ the subalgebra of the $\sigma$-algebra $\mathcal{A}$ and construct the space $\mathbf{L}_{2}^{0}$ of random variables that are measurable with respect to $\mathcal{A}_{0}$. Obviously, $\mathbf{L}_{\mathbf{2}}^{\mathbf{0}}$ is a subspace of the space $\mathbf{L}_{\mathbf{2}}$. Let $\xi \in \mathbf{L}_{\mathbf{2}}$, then $\Pi \xi$, where $\Pi: \mathbf{L}_{\mathbf{2}} \rightarrow \mathbf{L}_{\mathbf{2}}^{0}$ is an orthoprojector, is called a conditional expectation of a random variable $\xi$ and is denoted by $\mathbf{E}\left(\xi \mid \mathcal{A}_{0}\right)$.

Let us consider two mappings: the first mapping $f: \mathfrak{I} \rightarrow \mathbf{L}_{2}$, which puts to each $t \in \mathfrak{I}, \mathfrak{I} \subset \mathbb{R}$ the random variable $\xi \in \mathbf{L}_{\mathbf{2}}$ in the correspondence, and the second mapping $g: \mathbf{L}_{\mathbf{2}} \times \Omega \rightarrow \mathbb{R}$, which puts to each pair $(\xi, \omega)$ the point $\xi(\omega) \in \mathbb{R}$ in the correspondence.

The mapping $\eta: \mathfrak{I} \times \Omega \rightarrow \mathbb{R}$, having the form $\eta=\eta(t, \omega)=g(f(t), \omega)$, is called the (one-dimensional) random process. Following [8], the random process $\eta$ is called continuous, if a.s. all its trajectories are continuous. Let us denote by the $\mathbf{C L}_{\mathbf{2}}$ the set of the continuous random processes, which forms a Banach space. Continuous random process, which (independent) random variables are Gaussian (i.e. have the normal (Gauss) distribution), is called Gaussian. A one-dimensional Wiener process $\beta=\beta(t)$ is an example of the continuous process, and it has the following properties:

$(\mathrm{W} 1)$ a.s. $\beta(0)=0$, a.s. all its thajectories $\beta(t)$ are continuous, and for all $t \in \overline{\mathbb{R}}_{+}(=$ $\{0\} \cup \mathbb{R})$ the random variable $\beta(t)$ is Gaussian; 
(W2) the mathematical expectation $\mathbf{E}(\beta(t))=0$ and autocorrelation function $\mathbf{E}\left((\beta(t)-\beta(s))^{2}\right)=|t-s|$ for all $s, t \in \overline{\mathbb{R}}_{+} ;$

(W3) trajectories $\beta(t)$ are not differentiable in each point $t \in \overline{\mathbb{R}}_{+}$and they have an unbounded variation on the each arbitrarily small interval.

Remark 1. Note, that the properties (W1) and (W2) played the important role for the definition of the Wiener process, and the property (W3) is followed from the first two.

Theorem 1. Then there exists the unique random process $\beta$, satisfying properties (W1) - (W2) with probability one, and it can be present in the form

$$
\beta(t)=\sum_{k=0}^{\infty} \zeta_{k} \sin \frac{\pi}{2}(2 k+1) t,
$$

where $\zeta_{k}$ are independent Gaussian variables, $\mathbf{E} \zeta_{k}=0, \mathbf{D} \zeta_{k}=\left[\frac{\pi}{2}(2 k+1)\right]^{-2}$, where by the $\mathbf{E}, \mathbf{D}$ the mathematical expectation and the dispertion of the random variable are denoted.

Now fix $\eta \in \mathbf{C L}_{2}$ and $t \in \mathfrak{I}(=(\varepsilon, \tau) \subset \mathbb{R})$ and by the $\mathcal{N}_{t}^{\eta}$ let us denote $\sigma$-algebra, generating by the random variable $\eta(t)$. Denote $\mathbf{E}_{t}^{\eta}=\mathbf{E}\left(\cdot \mid \mathcal{N}_{t}^{\eta}\right)$.

Definition 1. Let be $\eta \in \mathbf{C L}_{\mathbf{2}}$, the random variable

$$
\begin{gathered}
D \eta(t, \cdot)=\lim _{\triangle t \rightarrow 0+} E_{t}^{\eta}\left(\frac{\eta(t+\triangle t, \cdot)-\eta(t, \cdot)}{\triangle t}\right) \\
\left(D_{*} \eta(t, \cdot)=\lim _{\triangle t \rightarrow 0+} E_{t}^{\eta}\left(\frac{\eta(t, \cdot)-\eta(t-\triangle t, \cdot)}{\triangle t}\right)\right)
\end{gathered}
$$

is called the mean derivative on the right $D \eta(t, \cdot)$ (on the left $D_{*} \eta(t, \cdot)$ ) of the random process $\eta$ at the point $t \in(\varepsilon, \tau)$, if there exists the limit in the sense of the uniform metrics on $\mathbb{R}$. The random process $\eta$ is called mean differentiable on the right (on the left) on $(\varepsilon, \tau)$, in the there exists the mean derivative on the right (on the left) in each point $t \in(\varepsilon, \tau)$.

Let the random process $\eta \in \mathbf{C L}_{2}$ be mean differentiable on the right and on the left on $(\varepsilon, \tau)$. Define the symmetrical mean derivative $\stackrel{o}{\eta}=D_{S} \eta=\frac{1}{2}\left(D+D_{*}\right) \eta$, and further we will call it by the Nelson - Gliklikh derivative. By the $\stackrel{o}{\eta}^{(l)}, l \in \mathbb{N}$, let us denote the $l$-th derivative of Nelson - Gliklikh of the random process $\eta$.

Theorem 2. (Yu.E. Gliklikh, [13]) Let $\beta=\beta(t)$ be the Wiener process, then $\stackrel{o}{\beta}(t)=\frac{\beta(t)}{2 t}$ for all $t \in \mathbb{R}_{+}$.

Remark 2. (i) Note, that the Nelson - Gliklikh derivative of the Wiener process has the property of linearity:

$$
\left(\alpha_{1} \beta_{1}(t) \stackrel{o}{+} \alpha_{2} \beta_{2}(t)\right)=\alpha_{1} \stackrel{o}{\beta_{1}}(t)+\alpha_{2} \stackrel{o}{\beta_{2}}(t)
$$

(ii) Note, that if the trajectories of the random process $\eta$ are a.s. continuously differentiable in the "ordinary case" on $(\varepsilon, \tau)$, then its Nelson - Gliklikh derivative coincides with the "ordinary" derivative. Therefore, consistently applying the formula of 
differentiation of the quotient, we obtain, that $l$-th Nelson - Gliklikh derivative of Wiener process satisfies

$$
\stackrel{o}{\beta}^{(l)}(t)=(-1)^{l-1} \cdot \prod_{i=1}^{l-1}(2 i-1) \cdot \frac{\beta(t)}{(2 t)^{l}}, \quad l \in \mathbb{N}, \quad l \geq 2
$$

Let us introduce space $\mathbf{C}^{l} \mathbf{L}_{2}, l \in \mathbb{N}$, of the random processes from $\mathbf{C L}_{2}$, which trajectories are a.s. differentialble in the sense of Nelson - Gliklikh on the set $\mathfrak{I}$ until the order $l$. If $\mathfrak{I} \subset \mathbb{R}_{+}$, then it follows from the Theorem 2 , that there exists the derivative $\stackrel{o}{\beta \in} \mathbf{C}^{1} \mathbf{L}_{2}$, which is called (a one-dimensial) "white noise". Futher the spaces $\mathbf{C}^{l} \mathbf{L}_{2}$ we will call the spaces of differentiable "noises".

Next we choose a monotonically decreasing numerical sequence $K=\left\{\mu_{k}\right\}$, such that $\lim _{k \rightarrow \infty} \mu_{k}=0$ and the numerical series $\sum_{k=1}^{\infty} \mu_{k}<+\infty$. Take the sequence of independent random processes $\left\{\eta_{k}\right\}$ and define a random $K$-process

$$
\Theta_{K}(t)=\sum_{k=1}^{\infty} \sqrt{\mu_{k}} \eta_{k}(t) \varphi_{k}
$$

which provides that the series (6) converges uniformly on any compact set from $\mathfrak{I}$. We introduce the Nelson - Gliklikh derivatives of random $K$-process

$$
\stackrel{o}{\Theta}_{K}^{(l)}(t)=\sum_{k=1}^{\infty} \sqrt{\mu_{k}} \stackrel{o}{\eta}_{k}^{(l)}(t) \varphi_{k}
$$

by the condition that on the right-hand side (7) there are derivatives up to the order $l$ inclusive and all series converge uniformly on any compact set in $\mathfrak{I}$. Futher consider the space $\mathbf{C}_{K} \mathbf{L}_{2}$ of the random $K$-processes, which trajectories are a.s. continuous, and the spaces $\mathbf{C}_{K}^{l} \mathbf{L}_{2}$ of random $K$-processes, which trajectories are a.s. continuously differentianle in the sense of Nelson - Gliklikh up to the order $l \in \mathbb{N}$ inclusive.

We define the Wiener $K$-process on the $\overline{\mathbb{R}}_{+}$by the formula

$$
W_{K}(t)=\sum_{k=1}^{\infty} \sqrt{\mu_{k}} \beta_{k}(t) \varphi_{k}
$$

where $\beta_{k}(t)$ has the properties (W1) и (W2).

Theorem 3. Let $K=\left\{\mu_{k}\right\}$ be a monotone numerical sequence, such that $\lim _{k \rightarrow \infty} \mu_{k}=0$ and $\sum_{k=1}^{\infty} \mu_{k}<+\infty$. Then with probability one there exist the unique Wiener K-process, which satisfies the conditions (W1) - (W3), and it can be rewritten in the form (7).

Let us consider the spaces of sequences $\mathbf{l}_{q}^{m} \mathbf{L}_{2}$ of random variables $\omega=\left(\omega_{1}, \omega_{2}, \ldots\right)$ with the norm

$$
\|\| \omega \|_{q}^{m}=\left(\sum_{k=1}^{\infty}\left(\lambda_{k}^{m} \mathbf{D} \omega_{k}\right)^{\frac{q}{2}}\right)^{\frac{1}{q}}, \quad q \in[1, \infty), m \in \mathbb{R} .
$$


Obviously, the imbeddings $\mathbf{l}_{q}^{m} \mathbf{L}_{2} \hookrightarrow \mathbf{l}_{q}^{n} \mathbf{L}_{2}$ are dense and continuous for all $m \geq n$ and $q \in[1, \infty)$, and the operator $\Lambda: \mathbf{l}_{q}^{m+2} \mathbf{L}_{2} \rightarrow \mathbf{l}_{q}^{m} \mathbf{L}_{2}$ is linear, continuous and continuously invertible for all $m \in \mathbb{R}$ and $q \in[1, \infty)$. Futher let us consider the spaces $\mathbf{C}_{K}^{l} \mathbf{l}_{q}^{m} \mathbf{L}_{2}(\equiv$ $\left.\mathbf{C}_{K}^{l} \mathbf{l}_{q}^{m} \mathbf{L}_{2}(\varepsilon, \tau),(\varepsilon, \tau) \subset \mathbb{R}\right)$ of random $K$-processes $\eta=\left(\eta_{1}, \eta_{2}, \ldots\right), \eta_{k}=\eta_{k}(t), t \in(\varepsilon, \tau), k \in$ $\mathbb{N}$, which Nelson - Gliklikh derivatives up to order $l \in\{0\} \cup \mathbb{N}$ inclusive are a.s. continuous on $(\varepsilon, \tau)$. Consider the Wiener $K$-process

$$
W_{K}=\left(\sqrt{\mu_{1}} \beta_{1}, \sqrt{\mu_{2}} \beta_{2}, \ldots\right)
$$

where $\beta_{k}=\beta_{k}(t), t \in \mathbb{R}_{+}$, are Brownian motions of the form (5). Note, that if the series

$$
\sum_{k=1}^{\infty} \mu_{k}^{\frac{q}{2}} \lambda_{k}^{\frac{m q}{2}}
$$

converges, then Wiener $K$-process $W_{K} \in \mathbf{C}_{K}^{l} \mathbf{l}_{q}^{m} \mathbf{L}_{2}$. By the thadition [8], the Nelson Gliklikh derivative $\stackrel{o}{W}_{K}(t)=(2 t)^{-1} W_{K}(t)$ of the Wiener $K$-process is called "white noise".

\section{Stochastic Sobolev Type Equations with Relatively $p$-Bounded Operators}

Let us move on to the finding the sufficient conditions of the existence and uniqueness of the solution of Showaler - Sidorov problem (3), (4). The foundation of our research are the theory of degenerate groups of operators and the phase space method for a degenerate Sobolev type equation (1), described in [7] in the deterministic case, which were successfullty transfered to the stochastic case [8-11]. We present the necessary information on the theory of degenerate groups operators [7], and consider Banach spaces $\mathfrak{U}$ and $\mathfrak{F}$, linear and bounded operators $L, M \in \mathcal{L}(\mathfrak{U} ; \mathfrak{F})$. Following the classical work [7], let us conside $L$-resolvent set $\rho^{L}(M)=\left\{\mu \in \mathbb{C}:(\mu L-M)^{-1} \in \mathcal{L}(\mathfrak{F} ; \mathfrak{U})\right\}$ and $L$-spectrum $\sigma^{L}(M)=\mathbb{C} \backslash \rho^{L}(M)$ of the operator $M$. If the $L$-specturm $\sigma^{L}(M)$ of the operator $M$ is bounded, then the operator $M$ is called $(L, \sigma)$-bounded. If the operator $M$ is $(L, \sigma)$ bounded, then the operators

$$
P=\frac{1}{2 \pi i} \int_{\gamma} R_{\mu}^{L}(M) d \mu \in \mathcal{L}(\mathfrak{U}), \quad Q=\frac{1}{2 \pi i} \int_{\gamma} L_{\mu}^{L}(M) d \mu \in \mathcal{L}(\mathfrak{F})
$$

are projectors. Here $R_{\mu}^{L}(M)=(\mu L-M)^{-1} L$ is a right, and $L_{\mu}^{L}(M)=L(\mu L-M)^{-1}$ is $a$ left L-resolvent of the operator $M, \gamma \subset \mathbb{C}$ is the contour bounding the domain containing $\sigma^{L}(M)$. Let $\mathfrak{U}^{0}\left(\mathfrak{U}^{1}\right)=\operatorname{ker} P(\operatorname{im} P), \mathfrak{F}^{0}\left(\mathfrak{F}^{1}\right)=\operatorname{ker} Q(\operatorname{im} Q)$ and by the $L_{k}\left(M_{k}\right)$ denote the restriction of the operator $L(M)$ on $\mathfrak{U}^{k}, k=0,1$.

Theorem 4. (Splitting theorem, [7]) Let the operator $M$ be $(L, \sigma)$-bounded. Then

(i) the action of the operators $L_{k}\left(M_{k}\right) \in \mathcal{L}\left(\mathfrak{U}^{k} ; \mathfrak{F}^{k}\right), k=0,1$ is observed;

(ii) there exist operators $M_{0}^{-1} \in \mathcal{L}\left(\mathfrak{F}^{0} ; \mathfrak{U}^{0}\right)$ and $L_{1}^{-1} \in \mathcal{L}\left(\mathfrak{F}^{1} ; \mathfrak{U}^{1}\right)$.

Then by Theorem 4 in the case of $(L, \sigma)$-boundness of the operator $M$ we can construct the operators $H=M_{0}^{-1} L_{0} \in \mathcal{L}\left(\mathfrak{U}^{0}\right), S=L_{1}^{-1} M_{1} \in \mathcal{L}\left(\mathfrak{U}^{1}\right)$. 
Definition 2. Operator $M$ is called $(L, p)$-bounded, $p \in\{0\} \cup \mathbb{N}$, if $\infty$ is a point of the removable singularity (i.e. $H \equiv \mathbb{O}, p=0$ ) or the pole of order $p \in \mathbb{N}$ (i.e. $H^{p} \neq \mathbb{O}$, $\left.H^{p+1} \equiv \mathbb{O}\right)$ of the L-resolvent $(\mu L-M)^{-1}$ of operator $M$.

Let us consider Showalter - Sidorov problem (3), (4), where the operators $L=L(\Lambda)$ and $M=M(\Lambda)$ are the polynomials with real coefficients, and their degrees satisfy the relation

$$
\operatorname{deg} L \geq \operatorname{deg} M
$$

acting in the Banach space of sequences. Futher let be $\mathfrak{U}=\mathbf{l}_{q}^{m+2 \operatorname{deg} L} \mathbf{L}_{2}, \mathfrak{F}=\mathbf{l}_{q}^{m} \mathbf{L}_{2}, m \in \mathbb{R}$, $q \in \mathbb{R}_{+}$. It was shown in [5], that the operators $L, M \in \mathcal{L}(\mathfrak{U} ; \mathfrak{F})$. Let $K=\left\{\mu_{k}\right\}$ be a monotonically decreasing numerical sequence, such that $\lim _{k \rightarrow \infty} \mu_{k}=0$ and the numerical series $\sum_{k=1}^{\infty} \mu_{k}<+\infty$.

Lemma 1. [5] Let the condition (10) be satisfied and the polynomials $L=L(s)$ and $M=M(s)$ have only real roots and have no common roots. Then the operator $M$ is $(L, 0)$-bounded.

Definition 3. Let us call a random K-process $\eta \in \mathbf{C}_{K}^{1} \mathbf{l}_{q}^{m} \mathbf{L}_{2}(0, \tau)$ a classical solution of equation (3), if a.s. all its trajectories satisfy equation (3) for all $t \in(0, \tau)$. Moreover, if the solution $\eta=\eta(t)$ of equation (3) satisfies condition (4), we will call it a classical solution of problem (3), (4).

In the work [12] the sufficient conditions of the existence of unique classical solution of abstract problem (3), (4) were found. Let write the initial random variable $\eta_{0}$ in the form

$$
\eta_{0}=\sum_{k=1}^{\infty} \eta_{0 k} \sqrt{\mu_{k}} e_{k}
$$

Here the random variables $\eta_{0 k} \in \mathbf{L}_{2}$ are uniformly bounded, i.e. there exists such number $C_{0}>0$, that $\mathbf{D} \eta_{0 k}<C_{0}, \forall k \in \mathbb{N}$. Then in the case of arbitrarily operators $L$ and $M$ the Theorem is hold.

Theorem 5. [12] Let the operator $M$ be $(L, p)$-bounded, $p \in\{0\} \cup \mathbb{N}$. Then for each $N \in$ $\mathcal{L}(\mathfrak{U} ; \mathfrak{F})$, each random $K$-process $\Theta=\Theta(t)$ such, that $(\mathbb{I}-Q) N \Theta \in \mathbf{C}_{K}^{p+1} \mathbf{l}_{q}^{m} \mathbf{L}_{2}$ and $Q N \Theta \in$ $\mathbf{C}_{K} \mathbf{l}_{q}^{m} \mathbf{L}_{2}$ is satisfied, and for each random variable $\eta_{0} \in \mathbf{l}_{q}^{m} \mathbf{L}_{2}$, not depending on $\Theta$ for every fixed $t$, there exists the unique solution $\eta \in \mathbf{C}_{K}^{1} \mathbf{l}_{q}^{m} \mathbf{L}_{2}$ of problem (3), (4), which has the form

$$
\eta(t)=U^{t} \eta_{0}+\int_{0}^{t} U^{t-s} L_{1}^{-1} Q N \Theta(s) d s-\sum_{q=0}^{p} H^{q} M_{0}^{-1}(\mathbb{I}-Q) N \stackrel{o}{\Theta}(t) .
$$

Here

$$
U^{t} \eta_{0}=\sum_{k: \nu_{k} \in \sigma^{L}(M)} e^{\nu_{k} t} \eta_{0 k} \sqrt{\mu_{k}} e_{k}
$$

The proof of Theorem 5 is based on the methods of the theory of degenerate groups of solving operators [7] as in the deterministic case. Now we turn to problem (3), (4), where as an external impact we consider "white noise" $\Theta=\stackrel{o}{W}{ }_{K}(t)$. 
Theorem 6. Let condition (10) be satisfied and the polynomials $L=L(s)$ and $M=M(s)$ have only real roots and have no common roots. Then for each $N \in \mathcal{L}(\mathfrak{U} ; \mathfrak{F})$, every sequence $K$ such, that the conditions $(\mathbb{I}-Q) N W_{K}(t) \in \mathbf{C}_{K}^{1} \mathbf{l}_{q}^{m} \mathbf{L}_{2}$ and $Q N W_{K}(t) \in \mathbf{C}_{K} \mathbf{l}_{q}^{m} \mathbf{L}_{2}$ are satisfied, and for each random variable $\eta_{0} \in \mathbf{l}_{q}^{m} \mathbf{L}_{2}$, not depending on $W_{K}$ for every fixed $t$, there exists the unique solution $\eta \in \mathbf{C}_{K}^{1} \mathbf{l}_{q}^{m} \mathbf{L}_{2}$ of problem (3), (4), which have the form

$$
\eta(t)=U^{t} \eta_{0}+L_{1}^{-1}\left[Q N W_{K}(t)-M_{1} \int_{0}^{t} U^{t-s} L_{1}^{-1} Q N W_{K}(s) d s\right]-M_{0}^{-1}(\mathbb{I}-Q) N \stackrel{o}{W_{K}}(t) .
$$

Here

$$
\begin{gathered}
U^{t} \eta_{0}=\sum_{k=1}^{\infty} e^{\nu_{k} t} \eta_{0 k} \sqrt{\mu_{k}} e_{k}, \\
L_{1}^{-1} \Xi=\sum_{k=1}^{\infty} \frac{\xi_{k} e_{k}}{L\left(\lambda_{k}\right)}, \quad M_{1} \Xi=\sum_{k=1}^{\infty} M\left(\lambda_{k}\right) \xi_{k} e_{k}, \quad M_{0}^{-1} \Xi=\sum_{k: L\left(\lambda_{k}\right)=0} \frac{\xi_{k} e_{k}}{M\left(\lambda_{k}\right)}, \\
\Xi=\left\{\xi_{k}\right\},
\end{gathered}
$$

$\nu_{k}=\frac{M\left(\lambda_{k}\right)}{L\left(\lambda_{k}\right)}$ are the points of $L$-spectrum $\sigma^{L}(M)$ of operator $M$; vectors $e_{k}=$ $(0, \ldots, 0,1,0, \ldots)$, where the unit stands on the $k$-th place; the sign' means the absence of $k$-th members of a series of such, that the polynomial $L\left(\lambda_{k}\right)$ is equal to zero.

Remark 3. The proof of Theorem 6 is based on the results of Theorem 5 and the limiting transition proposed in the paper [8]. Since "white noise" $\Theta(t)=(2 t)^{-1} W_{K}(t)$ is not differentiable in the case $t=0$, by the analogue in [8] and by the definition of the Nelson - Gliklikh derivative for all $\varepsilon \in(0, t), t \in \mathbb{R}_{+}$, integrating by parts the second term in right side (12) we get:

$$
\begin{gathered}
\int_{\varepsilon}^{t} U^{t-s} L_{1}^{-1} Q N \stackrel{o}{W_{K}}(s) d s=L_{1}^{-1} Q N W_{K}(t)-U^{t-\varepsilon} L_{1}^{-1} Q N W_{K}(\varepsilon)- \\
-S P \int_{\varepsilon}^{t} U^{t-s} L_{1}^{-1} Q N W_{K}(s) d s
\end{gathered}
$$

Then passing to the limit in (13) for $\varepsilon \rightarrow 0$, we obtain the reiquired, i.e.

$$
\int_{0}^{t} U^{t-s} L_{1}^{-1} Q N \stackrel{o}{W}{ }_{K}(s) d s=L_{1}^{-1} Q N W_{K}(t)-S P \int_{0}^{t} U^{t-s} L_{1}^{-1} Q N W_{K}(s) d s .
$$

Acknowledgements. The work was supported by Act 211 Government of the Russian Federation, contract No. 02.A03.21.0011.

\section{References}

1. Barenblatt G.I., Zheltov Iu.P., Kochina I.N. Basic Concepts in the Theory of Seepage of Homogeneous Liquids in Fissured Rocks [Strata]. Journal of Applied Mathematics and Mechanics, 1960, vol. 24, issue 5, pp. 1286-1303. DOI: 10.1016/0021-8928(60)90107-6

2. Hoff N.J. Creep Buckling. The Aeronautical Quarterly, 1956, vol. 7, no. 1, pp. 1-20. 
3. Keller A.V., Al-Delfi J.K. Holomorphic Degenerate Groups of Operators in Quasi-Banach Spaces. Bulletin of the South Ural State University. Series: Mathematics. Mechanics. Physics, 2015, vol. 7, no. 1, pp. 20-27.

4. Zamyshlyaeva A.A., Keller A.V., Sagadeeva M.A. On Integration in Quasi-Banach Spaces of Sequences. Journal of Computational and Engineering Mathematics, 2015, vol. 2, no. 1, pp. 52-56. DOI: $10.14529 /$ jcem 150106

5. Solovyova N.N., Zagrebina S.A., Sviridyuk G.A. Sobolev Type Mathematical Models with Relatively Positive Operators in the Sequence Spaces. Bulletin of the South Ural State University. Series: Mathematics. Mechanics. Physics, 2017, vol. 9, no. 4, pp. 27-35. DOI: $10.14529 / \mathrm{mmph} 170404$

6. Al-Isawi J.K.T., Zamyshlyaeva A.A. Computational Experiment for One Class of Evolution Mathematical Models in Quasi-Sobolev Spaces. Bulletin of the South Ural State University. Series: Mathematical Modelling, Programming and Computer Software, 2016, vol. 9, no. 4, pp. 141-147. DOI: $10.14529 / \mathrm{mmp} 160413$

7. Sviridyuk G.A., Fedorov V.E. Linear Sobolev Type Equations and Degenerate Semigroups of Operators. Utrecht, Boston, Köln, Tokyo, VSP, 2003. 216 p. DOI: $10.1515 / 9783110915501$

8. Sviridyuk G.A., Manakova N.A. Dynamic Models of Sobolev Type with the Showalter - Sidorov Condition and Additive "Noises". Bulletin of the South Ural State University. Series: Mathematical Modelling, Programming and Computer Software, 2014, vol. 7, no. 1, pp. 90-103. (in Russian) DOI: 10.14529/mmp140108

9. Favini A., Sviridyuk G.A., Manakova N.A. Linear Sobolev Type Equations with Relatively p-Sectorial Operators in Space of "Noises". Abstract and Applied Analysis, 2015, vol. 2015, Article ID 697410, 8 p. DOI: 10.1155/2015/697410

10. Favini A., Sviridyuk G.A., Zamyshlyaeva A.A. One Class of Sobolev Type Equations of Higher Order with Additive "White Noise". Communications on Pure and Applied Analysis, 2016, vol. 15, no. 1, pp. 185-196.

11. Favini A., Sviridyuk G.A., Sagadeeva M.A. Linear Sobolev Type Equations with Relatively pRadial Operators in Space of "Noises". Mediterranian Journal of Mathematics, 2016, vol. 13, no 6, pp. 4607-4621.

12. Sviridyuk G.A., Manakova N.A. The Barenblatt - Zheltov - Kochina Model with Additive White Noise in Quasi-Sobolev Spaces. Journal of Computational and Engineering Mathematics, 2016, vol. 3, no. 1, pp. 61-67. DOI: $10.14529 /$ jcem160107

13. Gliklikh, Yu.E. Investigation of Leontieff Type Equations with White Noise Protect by the Methods of Mean Derivatives of Stochastic Processes. Bulletin of the South Ural State University. Series Mathematical Modelling, Programming and Computer Software, 2012, no. 27 (286), issue 13 , pp. 24-34.

14. Nelson E. Dynamical Theories of Brownian Motion. Princeton, Princeton University Press, 1967.

15. Kovacs M., Larsson S. Introduction to Stochastic Partial Differential Equations. Proceedings of "New Directions in the Mathematical and Computer Sciences", National Universities Commission, Abuja, Nigeria, October 8-12, 2007. V. 4. Lagos, Publications of the ICMCS, 2008, pp. 159-232.

16. Melnikova I.V., Filinkov A.I., Alshansky M.A. Abstract Stochastic Equations II. Solutions in Spaces of Abstract Stochastic Distributions. Journal of Mathematical Sciences, 2003, vol. 116, no. 5 , pp. 3620-3656. DOI: $10.1023 / \mathrm{A}: 1024159908410$

Received September 14, 2017 


\title{
НЕКОТОРЫЕ МАТЕМАТИЧЕСКИЕ МОДЕЛИ С ОТНОСИТЕЛЬНО ОГРАНИЧЕННЫМ ОПЕРАТОРОМ И АДДИТИВНЫМ «БЕЛЫМ ШУМОМ» В ПРОСТРАНСТВАХ ПОСЛЕДОВАТЕЛЬНОСТЕЙ
}

\author{
К.В. Васючкова, Н.А. Манакова, Г.А. Свиридюк \\ Южно-Уральский государственный университет, г. Челябинск, \\ Российская Федерация
}

\begin{abstract}
Статья посвящена исследованию класса стохастических моделей математической физики на основе абстрактного уравнения соболевского типа в банаховых пространствах последовательностей, являющихся аналогами пространств Соболева. В качестве последовательностей, являющихся аналогами пространств Соболева. В качестве операторов берутся многочлены от аналога оператора Лапласа с действительными коэффициентами, и производится перенос теории линейных стохастических уравнений соболевского типа на банаховы пространства последовательностей. Вводятся пространства последовательностей дифференцируемых «шумов» и доказываются существование и единственность классического решения задачи Шоуолтера - Сидорова для стохастического уравнения соболевского типа с относительно ограниченным оператором. Построенная абстрактная схема может быть применена к исследованию широкого класса стохастических моделей математической физики, таких, например, как модель Баренблатта - Желтова - Кочиной и модель Хоффа.

Ключевые слова: уравнения соболевского типа; банаховы пространства последовательностей; производная Нельсона - Гликлиха; «белый шум».
\end{abstract}

\section{Литература}

1. Баренблатт, Г.И. Об основных представлениях теории фильтрации однородных жидкостей в трещиноватых породах / Г.И. Баренблатт, Ю.П. Желтов, И.Н. Кочина // Прикладная математика и механика. - 1960. - Т. 24, № 5. - С. 58-73.

2. Hoff, N.J. Creep Buckling / N.J. Hoff // The Aeronautical Quarterly. - 1956. - V. 7, № 1. P. 1-20.

3. Келлер, А.В. Голоморфные вырожденные группы операторов в квазибанаховых пространствах / А.В. Келлер, Д.К. Аль-Делфи // Вестник ЮУрГУ. Серия: Математика. Механика. Физика. - 2015. - Т. 7, № 1. - С. 20-27.

4. Zamyshlyaeva, A.A. On Integration in Quasi-Banach Spaces of Sequences A.A. Zamyshlyaeva, A.V. Keller, M.A. Sagadeeva // Journal of Computational and Engineering Mathematics. - 2015. - V. 2, № 1. - P. 52-56.

5. Solovyova, N.N. Sobolev Type Mathematical Models with Relatively Positive Operators in the Sequence Spaces / N.N. Solovyova, S.A. Zagrebina, G.A. Sviridyuk // Вестник ЮУрГУ. Серия: Математика. Механика. Физика. - 2017. - Т. 9, № 4. - С. 27-35.

6. Al-Isawi, J.K.T. Computational Experiment for One Class of Evolution Mathematical Models in Quasi-Sobolev Spaces / J.K.T. Al-Isawi, A.A. Zamyshlyaeva // Вестник ЮУрГУ. Серия: Математическое моделирование и программирование. - 2016. - Т. 9, № 4. - С. 141-147.

7. Sviridyuk, G.A. Linear Sobolev Type Equations and Degenerate Semigroups of Operators / G.A. Sviridyuk, V.E. Fedorov. - Utrecht; Boston; Köln; Tokyo: VSP, 2003. - 216 p.

8. Свиридюк, Г.А. Динамические модели соболевского типа с условием Шоуолтера - Сидорова и аддитивными «шумами» / Г.А. Свиридюк, Н.А. Манакова // Вестник ЮУрГУ. Серия: Математическое моделирование и программирование. - 2014. - Т. 7, № 1. C. $90-103$. 
9. Favini, A. Linear Sobolev Type Equations with Relatively p-Sectorial Operators in Space of «noises» / A. Favini, G.A. Sviridyuk, N.A. Manakova // Abstract and Applied Analysis. 2015. - V. 2015. - Article ID 697410. - 8 p.

10. Favini, A. One Class of Sobolev Type Equations of Higher Order with Additive «White Noise» / A. Favini, G.A. Sviridyuk, A.A. Zamyshlyaeva // Communications on Pure and Applied Analysis. - 2016. - V. 15, № 1. - P. 185-196.

11. Favini, A. Linear Sobolev Type Equations with Relatively p-Radial Operators in Space of «Noises»/ A. Favini, G.A. Sviridyuk, M.A. Sagadeeva // Mediterranian Journal of Mathematics. - 2016. - V. 13, № 6. - P. 4607-4621.

12. Sviridyuk, G.A. The Barenblatt - Zheltov - Kochina Model with Additive White Noise in Quasi-Sobolev Spaces / G.A. Sviridyuk, N.A. Manakova // Journal of Computational and Engineering Mathematics. - 2016. - V. 3, № 1. - P. 61-67.

13. Gliklikh, Yu.E. Investigation of Leontieff Type Equations with White Noise Protect by the Methods of Mean Derivatives of Stochastic Processes // Вестник ЮУрГУ. Серия: Математическое моделирование и программирование. - 2012. - № 27 (286), вып. 13. - С. 24-34.

14. Nelson, E. Dynamical Theories of Brownian Motion / E. Nelson. - Princeton: Princeton University Press, 1967.

15. Kovacs, M. Introduction to Stochastic Partial Differential Equations / M. Kovacs, S. Larsson // Proceedings of «New Directions in the Mathematical and Computer Sciences», National Universities Commission, Abuja, Nigeria, October 8-12, 2007. V. 4. - Lagos: Publications of the ICMCS, 2008. - P. 159-232.

16. Melnikova, I.V. Abstract Stochastic Equations II. Solutions in Spaces of Abstract Stochastic Distributions / I.V. Melnikova, A.I. Filinkov, M.A. Alshansky // Journal of Mathematical Sciences. - 2003. - V. 116, № 5. - P. 3620-3656.

Ксения Владимировна Васючкова, аспирант, ассистент кафедры «Уравнения математической физики», Южно-Уральский государственный университет (г. Челябинск, Российская Федерация), vasiuchkovakv@susu.ru.

Наталья Александровна Манакова, доктор физико-математических наук, доцент, профессор кафедры «Уравнения математической физики», Южно-Уральский государственный университет (г. Челябинск, Российская Федерация), manakova@susu.ru.

Георгий Анатольевич Свиридюк, доктор физико-математических наук, профессор, заведующий кафедрой «Уравнения математической физики», ЮжноУральский государственный университет (г. Челябинск, Российская Федерация), sviridyuk@susu.ru.

Поступила в редакиию 14 сентября 2017 г. 